\title{
Text-Map Analysis: An Introduction to the Method and an Examination of Relationship Self-Regulation and Religion
}

Joe M. Chelladurai

Brigham Young University - Provo

David C. Dollahite

Brigham Young University, david_dollahite@byu.edu

Loren D. Marks

Brigham Young University - Provo, loren_marks@byu.edu

Follow this and additional works at: https://scholarsarchive.byu.edu/facpub

Part of the Other Social and Behavioral Sciences Commons

\section{Original Publication Citation}

Chelladurai, J. M., Dollahite, D. C., \& Marks, L. D. (2020). Text-map analysis: An introduction to the method and an examination of relationship self-regulation and religion. Couple and Family Psychology: Research and Practice, 9, 45-58.

\section{BYU ScholarsArchive Citation}

Chelladurai, Joe M.; Dollahite, David C.; and Marks, Loren D., "Text-Map Analysis: An Introduction to the Method and an Examination of Relationship Self-Regulation and Religion" (2020). Faculty Publications. 4822.

https://scholarsarchive.byu.edu/facpub/4822

This Peer-Reviewed Article is brought to you for free and open access by BYU ScholarsArchive. It has been accepted for inclusion in Faculty Publications by an authorized administrator of BYU ScholarsArchive. For more information, please contact ellen_amatangelo@byu.edu. 


\title{
Text-Map Analysis: An Introduction to the Method and an Examination of Relationship Self-Regulation and Religion
}

\author{
Joe M. Chelladurai, David C. Dollahite, and Loren D. Marks \\ Brigham Young University
}

\begin{abstract}
The twofold purpose of this article is to (a) introduce text-map analysis and demonstrate its utility and (b) to examine systemic processes between relationship selfregulation and religion. In the first part, we propose a novel approach to qualitative data analysis termed mapping and analysis of processes and sequences. We then present procedural steps and diagrammatic conventions to chart sequences and connections between concepts and events using flowchart diagrams we call text-maps. In the second part, using text-map analysis with a case study, we examine relationship self-regulation and religion in a Latter-day Saint couple. We draw upon three episodes from the couple's marriage that were marked by relationship maintenance through selfregulation. We discuss the role of religion in relationship self-regulation and implications for research and practice. We also discuss the nature and limitations of the findings of the study and directions for future research.
\end{abstract}

Keywords: marriage, relationship self-regulation, religion, relationship maintenance, case study

Maps have been created by cartographers for several centuries to communicate topographical and geographical information. These visuals have aided travelers in navigating terrains, tracing paths, and marking waypoints, providing much valuable knowledge of what can be a complex reality. Extending this rationale to examine the complexities of human experience, we propose the need for diagrammatic methods to document chronological sequences and understand systemic processes. As an exercise, creating a visual map of significant events and interactive processes can help understand people's past journeys, current circumstances, and future hopes and prospects. To this end, we propose a novel approach to map systemic individual and relational processes using a sequence-based approach called mapping and

(D) Joe M. Chelladurai, (D) David C. Dollahite, and Loren D. Marks, School of Family Life, Brigham Young University.

Correspondence concerning this article should be addressed to Joe M. Chelladurai, School of Family Life, Brigham Young University, 2086 Joseph Fielding Smith Building, Provo, UT 84602. E-mail: joe.chelladurai@byu.edu analysis of processes and sequences (MAPS). This analysis is visually depicted using flowchart diagrams called text-maps.

\section{Mapping and Analysis of Processes and Sequences}

MAPS is based on sequence analysis involving the examination of qualitative text data by arranging systemic elements in chronological order to examine processes. Sequences are made up of temporally ordered events that may be helpful in providing an auditable review of contexts, circumstances, and interconnections. Although not necessarily causal or situated in order of importance, sequences can be very helpful in identifying patterns and significant events of decision and change (Abbott, 1995).

The MAPS approach to research inquiry is abductive by nature. In family studies, Daly (2007) proposed abduction as part of a recursive cycle of inquiry that includes induction and deduction. Based on Charles Sanders Peirce' pragmatism, Tavory and Timmermans (2014) defined abduction as "an inferential creative process of producing new hypothesis and theories based on surprising research evidence" (p. 
5). Drawing from this theoretical background, we propose MAPS as a theory-informed, datadriven methodology to analyze qualitative data. This approach acknowledges the positionality of the researcher in bringing preconceived theories while at the same time allowing for the possibility of generating new theoretical propositions through analytical and inferential iterations of data (Tavory \& Timmermans, 2014).

Text-map analysis is primarily a diagrammatic analysis that involves mapping processes and sequences. Diagrammatic representations provide an at-a-glance overview of processes, which can be a valuable tool for therapists and researchers. For example, ecomaps, genograms, drawings, and other visuals have been used across various therapeutic settings (Oster \& Crone, 2004). Recently known as visually enhanced therapy, these diagrams can help assist therapists and clients understand, record, and remember what was discussed during therapy sessions (Boisvert \& Ahmed, 2019).

Although, visuals are potentially helpful, they must be used with caution, as they may also have drawbacks if these tools depict oversimplification or lead to misdiagnosis. The words of Alfred Korzybski echo our concern, "A map is not the territory it represents, but, if correct, it has a similar structure to the territory, which accounts for its usefulness" (Korzybski, 1994, p. 58). The therapist must therefore play an active and guiding role working together with the client to construct and interpret the visuals by drafting, correcting, and adapting until a clear, accurate, and useful depiction is reached.

There are many varieties of qualitative approaches, and one may wonder about the need for yet another method. In contrast to qualitative methods, which thematically examine broad phenomena, text-map analysis can be helpful to sequentially examine specific processes and subprocesses. Moreover, text-map analysis helps identify specific antecedent and consequent events that situate pivotal decision points in context. Another major advantage is that textmap analysis is abductive, which allows researchers to utilize an analytic method that is both data-based and hypothesis-driven, thus bringing the best of both inductive and deductive worlds while maintaining its own unique methodological position. Text-map analysis is also versatile and can be used to conduct studies ranging from large-scale quantitative studies to small-sample qualitative and case studies.

In the following section, we provide general step-by-step guidelines to systematically conduct text-map analysis in qualitative research. Similar guidelines may be adapted for examining large samples by converting qualitative data into quantitative data using coding protocols for further statistical analysis. For example, an excellent application of sequence analysis and statistical testing is illustrated by Townsend and colleagues (2016), who identified patterns of self-harm in adolescents.

\section{Steps to Conduct Text-Map Analysis}

\section{Read}

Previous theoretical reviews and transcript(s) are read as a preparatory step for analysis. It is important to read the transcript(s) multiple times to gain a clear overview and to be open to new insights. In the first reading, the aim is to understand the broader context and to be attentive to the unfolding narrative and topics discussed. Highlighting and notetaking should be kept to a minimum to reduce distractions. In the second and further readings, the aim is to read for clarification and get a preliminary overview of sequences and processes.

\section{Identify}

Topics that are of interest that can benefit from sequential analysis are identified. It may be helpful to identify episodes that capture phenomenon in context and proximity to other possible antecedents and precedents. This can help bring focus on the topic or phenomena as well as identify key processes under investigation for further in-depth text-map analysis. The following three-step guideline can be used for identifying and selecting episodes: (a) Does the episode contain enough information on the topic under study? (b) Are there clearly outlined sequences as described by the participant? and (c) Do the episodes capture processes that are important from the participants' point of view?

\section{Code}

Coding is labeling units of information. In textmap analysis, this is achieved by two stages. In the first stage, through deductive coding, a code 
list is developed based on previous theories. Key concepts of informing theories, also known as theoretical codes, are identified and can be used as codes. In the second stage, coding is inductive and data driven. These codes are developed through open or in-vivo coding. Lineby-line and phrase-by-phrase coding is suggested. Representative phrases within the episode are identified and, if appropriate, are matched and labeled with theoretical codes.

\section{Draw}

In this step, we diagram sequences and processes using shapes and text. A brief proposed convention based on process diagrams is presented in Table 1. Text is presented through words or phrases identified during coding. Then, shapes, such as rectangles, diamonds, and circles, are drawn around the text. Next, these shapes are connected using arrows. To note, arrows do not imply correlation or causation. They are representative of sequences and possible conceptual connections based on data provided by the participant(s), either through their own words or through conceptual inference made by the therapist/researcher and the participant(s). Colors may also be used.

\section{Create}

In this final step, previous steps are synthesized to make theoretical inferences. With abductive reasoning (Daly, 2007), sequences and processes are superimposed with preexisting theoretical concepts or own theoretical propositions. Multiple iterations may be helpful to pro- vide credibility and arrive at confidence in the findings.

In summary, text-map analysis is conducted through these five steps: reading for review and clarity, identifying episodes for analysis, coding deductively and inductively, drawing sequences and processes, and creating and synthesizing concepts toward making theoretical inferences. Using these detailed steps in this section, we next demonstrate text-map analysis to examine the concept of relationship self-regulation using a case study of a religious couple.

\section{Relationship Self-Regulation and Religion: An Examination Using Text-Map Analysis}

Examining systemic relational processes in couple relationships can help understand how couples work together to achieve greater relational stability and functioning. To this extent, relationship self-regulation has been acknowledged as an important process in helping maintain and improve couple relationships (Halford, Lizzio, Wilson, \& Occhipinti, 2007). In this study, we examined the processes involved in relationship self-regulation in a religious couple by utilizing a case study methodology.

\section{Relationship Self-Regulation}

Relationship self-regulation refers to an individual's regulation of thought, affect, and behavior toward realizing relationship goals that are based on four processes: appraisal, selfdirected goal setting, implementation, and evaluation (Halford et al., 2007). Similarly, from a

Table 1

Description of Elements for Constructing Text-Maps

\begin{tabular}{ll}
\hline Shape & To depict an event of significant importance \\
\hline Rectangle & To connect a set of factors \\
Circle & To mark a point of decision \\
Arrow & To indicate the direction of sequence
\end{tabular}

Note. These symbols can be adapted or other symbols may be created to depict other emergent functions. 
family process framework, Broderick (1993) theorized the family as a goal-seeking, selfregulating system. In this theory, the executive function detects discrepancies between the archival function and the status function and then transfers this information to the context monitoring function, which assesses opportunities, resources, and constraints. These evaluations lead to the selection of a course of action that may have an impact on the family's status, resulting in a changed status.

Relationship self-regulation has been associated with higher commitment and forgiveness and relationship satisfaction and stability (Novak, Smith, Larson, \& Crane, 2018; Shafer, James, \& Larson, 2016). Moreover, selfregulation has been recognized as an important mechanism for relationship functioningsometimes exhibiting even stronger effects than communication (Halford et al., 2007). Furthermore, relationship self-regulation has been found to be an adaptive process in mediating family of origin climate and marital stability and satisfaction (Hardy, Soloski, Ratcliffe, Anderson, \& Willoughby, 2015).

Although relationship self-regulation has been mostly beneficial, in some contexts it may not be as helpful. First, relationship selfregulation in isolation, where one partner is making sole efforts when the other is disengaged, may not be as fruitful as shared communal pursuit. Second, relationship self-regulation may sometimes be misapplied or misunderstood as avoidance and disengagement, which can be a problem for relationship functioning (Impett et al., 2010). Third, when people suppress negative emotions without relationship-focused coping, it can be detrimental for relationships (Impett et al., 2012; Kramer, 1993).

\section{Religion and Self-Regulation}

Scholars have proposed that religion may influence self-regulation. Particularly, religion (a) influences goal-setting processes, including selection, sanctification, organization, and internalization, (b) promotes self-monitoring, (c) builds self-regulatory strength, and (d) prescribes religious "outputs" for self-change (McCullough \& Willoughby, 2009). Also, religion can provide clear standards, supply motivation, facilitate self-examination, and regulate affect (Geyer \& Baumeister, 2005) while also promot- ing relational reconciliation (Dollahite, Marks, \& Barrow, 2019).

Research on religion and self-regulation has examined some of these concepts in individuals, for example, how reminders of God influence goal pursuit (Laurin, Kay, \& Fitzsimons, 2012). However, there is little research on the selfregulatory role of religion directly in relationships. Based on previous research suggesting that religion influences individual self-regulation, we propose that religion may have similar and proximal effect in relationships. By using systemic theories of self-regulation, we hope to examine how religion may influence components of self-regulation while maintaining a systemic view of the processes (Broderick, 1993; Carver \& Scheier, 2001).

\section{How Religion May Influence Relationship Self-Regulation}

To our knowledge, there have been no studies examining religion and relationship selfregulation. Recent research on religion and relationships indicates that there can be potential positive and negative outcomes (Dollahite, Marks, \& Dalton, 2018). Religion may help sanctify marriage and family relationships and endow sacred meaning and purpose in marriages (Mahoney, 2013). Further, involvement in religious rituals can facilitate self-monitoring and confession (McCullough \& Willoughby, 2009). Religious efforts that reflect processes such as reconciliation through repentance and forgiveness may be the outputs that help in improving relationships between individuals (Dollahite et al., 2019). Furthermore, when these patterns are repeated through regular religious observances and practices, they may have a more sustainable function in relationship maintenance processes. Although religion can have these potentially healthy outcomes, it can be harmful when practiced in unhealthy ways (Dollahite et al., 2018).

\section{A Sequence-Based Approach to Examining Relationship Self-Regulation}

Although relationship self-regulation has been established as an important process in relationship functioning, it has yet to be studied comprehensively. In most studies, relationship self-regulation has been studied quantitatively 
using the Behavioral Relationship Self-Regulation Scale, which has a two-factor structure that measures relationship effort and strategies (Wilson, Charker, Lizzio, Halford, \& Kimlin, 2005). Although these subscales (effort and strategies) measure various aspects of relationship selfregulation including appraisal, evaluation, and change implementation, the essence of these individual competencies may be diluted in the composition. Also, important cognitive and emotional aspects of relationship self-regulation may be left unexamined. In this regard and in addition to quantitative approaches, a qualitative program of research can help researchers explore the depth and breadth of the selfregulatory processes, particularly in dyadic relationships (Girgždè, Keturakis, \& Sondaitė, 2014).

Text-map analysis provides an advantage for examining self-regulation because both utilize diagrams to depict temporal order of processes and events, thus matching method with theory. Also, text-map analysis is a relevant analytic method because it helps to capture simultaneous dyadic patterns proposed by family systems theory (Broderick, 1993). For this study, we chose a religious couple because previous research has found that religious beliefs and practices both can influence self-regulation (Laurin et al., 2012). Thus, using text-map analysis, we conducted an in-depth examination of specific selfregulatory and religious processes. In the following sections, we present the methodology of the current study and then demonstrate the process of conducting text-map analysis.

\section{Method}

\section{Participants}

Two married participants were selected from a larger project examining religion and family life. They were recruited through referrals from congregational leaders. At the time of the interview, the couple were heterosexual, middleclass, Caucasian, in their late 40s, with several children, and active members of The Church of Jesus Christ of Latter-day Saints. For the purpose of the article, we have provided pseudonymns for them: Amy and Matt. They had been married for over than 25 years with-as this article notes-varying levels of happiness and marital satisfaction at different points. Amy was a stay-at home mom and later worked at a care facility, whereas Matt previously worked for the military and later at a retail store.

\section{Procedure}

Qualitative data were collected through semistructured interviewing. The third author conducted the interview in the participants' home. Participants were interviewed jointly for about 90 min. Using a semistructured interview protocol (Appendix), they were interviewed in depth regarding how their religious beliefs and practices influenced their relationship and vice versa. The interview guide was prepared to facilitate intensive interviewing, which is based on open-ended questioning (Lofland, Snow, Anderson, \& Lofland, 2005). This provided opportunity for follow-up questions. Questions were organized by topic: marriage, parenting, challenges, and religious life. Each interview question was pretested before beginning data collection. The opportunity to respond first to the questions alternated with each question, and participants were encouraged to share relevant narratives and experiences. This ensured that enough data were furnished by both participants, and both were given equal opportunity to respond. Interviews were audio-recorded, transcribed verbatim, and checked. The study was approved by the university institutional review board, and participants provided informed consent before the interview commenced.

\section{Methodological Integrity}

In this section, we present details of the qualitative research processes that were taken to ensure methodological rigor and integrity (Levitt et al., 2018). We present these through three considerations of qualitative research reiterated by Pitney (2004): credibility, transferability, and dependability. Credibility refers to whether "the research findings capture what is really occurring in the context" (Pitney, 2004, p. 26). We approached credibility through the triangulation of sample selection, data collection, and data analysis. Participants were drawn as a result of third-party referral having fit the criteria of a couple with high degree of religious centrality. Data were collected through multipleinformant perspectives, in which both spouses were present and were given opportunities to take turns answering questions. The third author 
conducted the interview, the first author analyzed and coded the text using text-map procedures and the second author audited the research process.

Transferability refers to whether methods and findings can be used across other populations, as generalizability is not appropriate in qualitative research. Transferability of the method was anticipated through the detailed outlining of steps taken during data analysis. Also, an audit trail was maintained to keep track of the issues resolved during the methodological triangulation process. Transferability of findings was attempted by providing "think descriptions" by outlining the context of the participants' lives and using direct quotations to keep the findings "grounded" in the data (Levitt et al., 2018). The usage of several lines of text from the interview to aid the presentation of findings demonstrate a high degree of participant-centered description.

Dependability refers to whether particular findings are reasonable and based on the data (Pitney, 2004). This was done through checking of interview transcripts as well as ensuring consistency of major elements of theoretical paradigms during the criterion-based episode identification process. Finally, after the completion of the study, the methodological approach was assessed by a trained qualitative researcher who was not involved in the research process. In summary, these abovementioned methodological integrity measures and triangulatory approaches to data collection, analysis, and auditing procedures ensured methodological rigor and helped to minimize researcher bias.

\section{Reflexivity}

Reflexivity refers to the "the ways in which a researcher critically monitors and understands the role of the self in the research endeavor" (Daly, 2007, p. 188). The three authors are male. Therefore, it is possible that they did not accurately interpret gender-sensitive statements made by Amy and Matt. The first author is a final-year graduate student who was born and raised in southern India. The fact that he is not from the same cultural background as the participants potentially is both a strength and a limitation. It could be a strength because he may be less influenced by cultural assumptions about marriage, communication, and relational processes among American couples. It could be a limitation because he may not have been as culturally attuned to subtle meanings. The authors are family studies scholars, and the second author has training in marriage and family therapy. This disciplinary background means the authors are particularly sensitized to issues of family systems theory including communication, feedback loops, and relational processes. That the authors are not clinical psychologists means that they may not be as sensitized to the ways that individual psychology influences relationship processes.

The authors also identify as active members of the faith community of the participants. From an emic (insider) perspective, this orientation helped us understand beliefs and terms within the cultural context. For example, when participants referred to the phrase "together forever," we were able to interpret that as referring to beliefs regarding eternal marriage. However, we acknowledge that proximity to phenomena under investigation may be significant disadvantages for objectivity in the research process. We therefore emphasize participant reports and describe processes in context.

\section{Analysis Plan}

Using the five steps to conduct text-map analysis as outlined earlier, we identified three episodes for the study. The interview text was read by the first author, and episodes were identified using the episode identification criteria outlined earlier. Theoretical codes were developed using family process and self-regulation theories (Broderick, 1993; Carver \& Scheier, 2001). Example codes included goal, reference value, self-evaluation, operations, comparator, archival function, and feedback loops. In the Results section, we outlined and demonstrated the coding and diagramming processes and briefly summarized findings at the end of each episode.

\section{Results}

Amy and Matt had strong beliefs regarding a core Latter-day Saint doctrine called eternal marriage, which posits that marriage can continue even after death (Leonhardt et al., 2018). During the interview, it was evident that religion was an integral part of their daily life and relationships. To present our approach to analysis of how beliefs and practices influenced 
their relationship, we present three episodes of relationship self-regulation, as discussed by Amy and Matt. After presenting their own words, we summarize and construct a text-map to illustrate various self-regulatory processes that emerged during data analysis.

\section{Episode 1: Matt's Self-Evaluation}

When Amy and Matt were asked how they have influenced each other's involvement with religion, Matt explained that Amy's example led him to evaluate himself. Specifically, Matt spoke of how Amy's example in pursuing their goal of eternal marriage influenced his own self-regulation. He stated,

You cannot help [but be influenced by your spouse] when you're going to be a together [forever] family. She is a good example for me. She'll do a lot of things that I should be doing, and I'll think, "How come I don't do those things?" Sometimes she gets me prompted to do them.

In this response, Matt compared his actions, or inaction, with Amy's. Matt's positive regard of Amy's example reportedly led him to question his inaction and eventually encouraged him to realign himself toward their goal of eternal marriage.

\section{Text-Map Analysis of Episode 1}

For our analysis, we split this passage into sentences and coded them as follows:

Goal: "to be a together [forever] family."

Reference value: "She is a good example for me. She'll do a lot of things that I should be doing."

Self-evaluation: "How come I don't do those things?"
Operations: "Sometimes she gets me prompted to do them."

Next, we mapped these codes into separate boxes. We placed the reference value and selfevaluation codes into a comparator box. We then drew arrows indicating the sequence of this process and a final arrow connecting the operations back to the comparator (feedback loop). We illustrated the text-map of Matt's reported self-regulation process as reported in Figure 1.

This exercise allowed us to capture an "at-aglance" view of self-regulatory components and processes and provided additional contextual understanding. We traced the sequential path from a higher order abstract goal (eternal marriage) to a specific comparative function (Amy's example) that bridged the goal and the operation. This visual description enabled us to connect concepts with narrative data simultaneously, thereby facilitating a systemic and dyadic perspective.

\section{Episode 2: Amy and Matt's Decision}

In Episode 2, Amy recollected the early years of their marriage. At one point, 2 years into their marriage, they attempted to go through marriage without religion:

We tried to do it both ways. We tried to do it the "church way" and then we tried to do it the "without the church" way. [I thought then], "I don't have to go church." .. I I was young, and I thought, "Okay, well I'll try it this other way."

Amy then reached a point when she felt her feelings toward her marriage were breaking down and she felt she and Matt needed help. She continued,

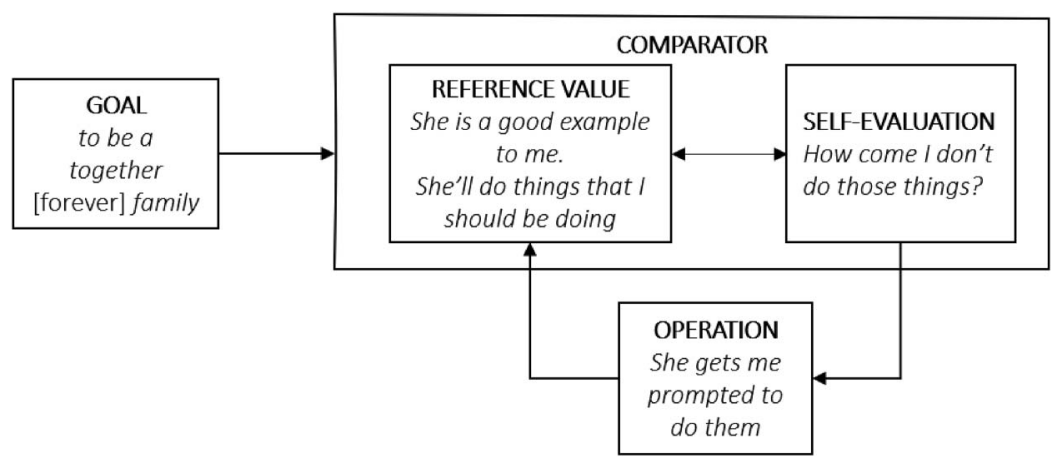

Figure 1. Text-map of Matt's self-evaluation (Episode 1). 
We had to do it one little step at a time by going back to church. ... We started learning together again. My faith grew because I chose to do it. . . . That's when we started growing. . . . We set a goal of having this eternal marriage, and we had to work really hard on it. . . We had to work out all the bumps of how to bond [with] each other. . . . We had to make choices. ... We couldn't live in both worlds.

Amy and Matt explored a different path and lifestyle and were reportedly not able to sustain their goals for their marriage without a religious environment. They later decided to return to religious activity, strengthen their religious beliefs, and focus on their marriage. In this pursuit and through a series of choices and actions, they "started learning together again" and reportedly facilitated a conducive environment for relationship maintenance and enhancement. Based on their statements and reflections, these goals were jointly pursued and done together, thereby representing couple unity and synergyelements that may be vital elements of healthy relationship self-regulation.

\section{Text-Map Analysis of Episode 2}

Recalling Matt and Amy's initial attitudes regarding marriage, especially "together forever" or "eternal marriage" as an important spiritual and relational goal, we entered the phrase "to have an eternal marriage" in a box and labeled it goal. Two years into their marriage, Amy's self-awareness and self-evaluation prompted a prospective response toward her marriage and family. We entered this aspect in a different box and labeled it as self-monitoring. Next, Amy stated, "we made a choice," suggesting an important decision point. We identified this point with a diamond symbol. This decision was followed by a series of actions such as "go back to our roots," "get a testimony," and "going back to church." We labeled these actions as operations. Finally, we connected these boxes with arrow marks indicating the sequence of these events (Figure 2).
At a preliminary level, we mapped the sequence of events in separate boxes, which enabled us to visualize the process of selfregulation at a reportedly crucial time in Matt and Amy's relationship. Along with this visual description and summary, we noted latent subprocesses, including (a) retrieval of archival function manifested through returning to a religious lifestyle and (b) changes from extrinsic to intrinsic religiosity indicated by their turn toward religion to pursue their relational goal.

\section{Episode 3: Falling Out of Love and Back in Love Again}

During the interview, Amy mentioned a period of time later on in their marriage, when she was concerned about falling out of love:

If we do not work at our marriage, whether it is faith
based or not, if we do not work at it, you can have ...
it's the little itty-bitty worms that eat at your love. The
toothpaste, the shoes left out, or whatever. They just
start gnawing at you and irritating you. You can find
yourself ... falling out of love. I found myself really
bogged down with motherhood and feeling over-
whelmed. I think it was about the time I had my fourth
child in 4 years. We had a couple of other older kids,
and I was feeling very overwhelmed, doing a lot of
things in the church. Huge responsibilities and just
trying to be the perfect mom and having the clean
house and doing everything that I knew how. I found
myself letting the little things start to eat at me.

He seemed to be, I thought, in a glamourous life where he was working in a retail store, and he was meeting people, and it's not that I wanted to be there, but I just didn't have a part of that life with him. I didn't know how to share that with him. It may have been a form of depression. I do not know. I didn't feel like that's what it was, but I found I started getting aggravated at everything he did until one day I woke up and I turned over and I looked at him and it was just like "I don't even know who you are!" It was the most awful feeling. It was just like, it was not that the love was gone, but it was just like, "I don't even know who you are." I felt sort of dead inside or something. I remember thinking, when that thought came to me, having absolutely total fear, just absolutely, "What's happened? What's happened?" So, I did what I knew to do

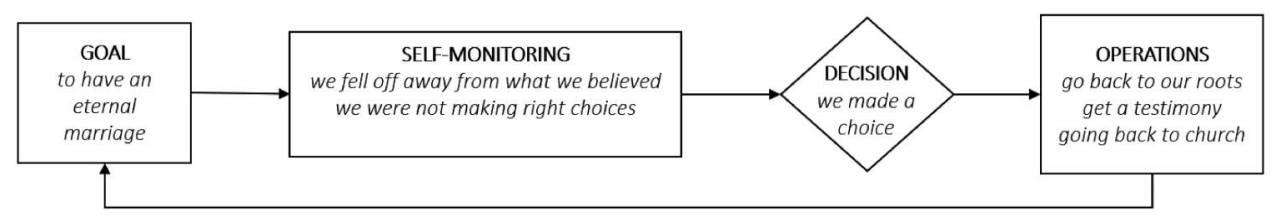

Figure 2. Text-map of Matt and Amy's decision (Episode 2). 
and that was just go to [God] and pray. I prayed for several days, because I was just feeling irritated and not very loving. I started praying because I knew that what I was feeling was not going to be conducive to. . . . I could see how it was going to erode our relationship.

I was really afraid to talk to Matt about it because I knew that I didn't know how to express that. I didn't know how he would take that. I was afraid he would think that I was saying I didn't love him anymore. That's not exactly what I was feeling, but I was feeling something that was scaring me. So, I started praying to God hoping to get an answer to how do I deal with this? I was scared to share it with anybody. Finally, the thought came to me just out of the blue, and I know it came from God. That [thought] was, "Why did you fall in love with him in the first place?" I start[ed] going back to ... we had a huge memory bank, and I do not know when I fell in love, it was just ... there. So, I didn't even have that resource to [say], "Oh, I remember the moment! I remember the things that made me want to be with him." I had to go back through those things. I decided that's what the feeling was, that I needed to do that. I needed to constantly go back to the things, [points] where I was attracted to him and what endeared him to me and made me love him.

As I started going back through those things, every ... time he did something, and I wanted to scream at him or be mad at him. I started making myself go back to the good things. Well, that love that I felt then came back. It washed over me. . . I I fell back in love. I mean, it was just a total fall back in[to] love. Everything that I ever felt about him was there.

I have always felt that was such a blessing in my life because I do not believe I'm the only person that has had those things happen where you kind of fall in and out of love with each other during your marriage. If you do not grab it before you continue down that slope of being out of love and get it back where you know it needs to go in order to make it [work], I think that's where ... marriages can fall apart.

In summary, Amy assessed her status regarding her increasingly negative feelings toward Matt and reportedly felt the need to change those feelings. She prayed to God and felt impressed looking back at the things that helped her to love Matt. She recollected memories and retrieved them when she was irritated. Eventually, she was able to increase her relationally facilitative emotions and reportedly navigated to a "total fall back in[to] love."

In addition to the sequence of these events, we noted the coming together of cognitive, affective, and behavioral aspects of self-regulation. What initially appeared as a cognitive process evidenced in her comparative function (thinking that Matt had a "glamourous life") was also connected with affective elements such as feeling overwhelmed, irritated, aggravated, and eventually "total fear." Even so, these emotions were reportedly overturned with a series of intentional cognitive adjustments including restraining from anger by retrieving from "a huge memory bank" (archival function) and focusing on the reasons why she loved Matt. Together, these cognitive and affective adjustments led to decisions such as praying for help, focusing on emotional regulation, and "falling back into love again."

\section{Text-Map Analysis of Episode 3}

After conceptually coding this extensive excerpt from the interview text, we noted a conceptual sequence of self-regulatory processes. In conceptual terms, Amy was selfaware of her deteriorating feelings of love toward Matt. Her decision to change reportedly occurred through praying about her deep concerns. These operations reportedly helped her to tap into preexisting resources through the archival function and use positive memories, recollections, and foci to avoid the incapacitation and further deterioration of love in her marriage. Using the text-map analysis, we noticed the important role of monitoring negative responses to external influence (e.g., irritation with Matt), as well as the role of positively using archival functions that helped Amy recall strengths and positive elements from the past. The utilization of facilitative spiritual, cognitive, affective, and behavioral processes systemically worked to reportedly help Amy "fall back in love" with Matt and reportedly rejuvenate their marriage. We undertook the same exercise outlined earlier in this section and produced an illustrative text-map (Figure 3).

\section{Discussion}

For this couple, religion reportedly influenced relationship self-regulation in several ways. In fact, it had such a pervasive influence that almost all aspects of self-regulatory processes involved religious processes. Religion influenced goal-setting, offered pathways to accomplish those goals through a hierarchical arrangement of subgoals, provided meaning to make difficult decisions, and facilitated a sense of efficacy through resulting incentives. Fur- 


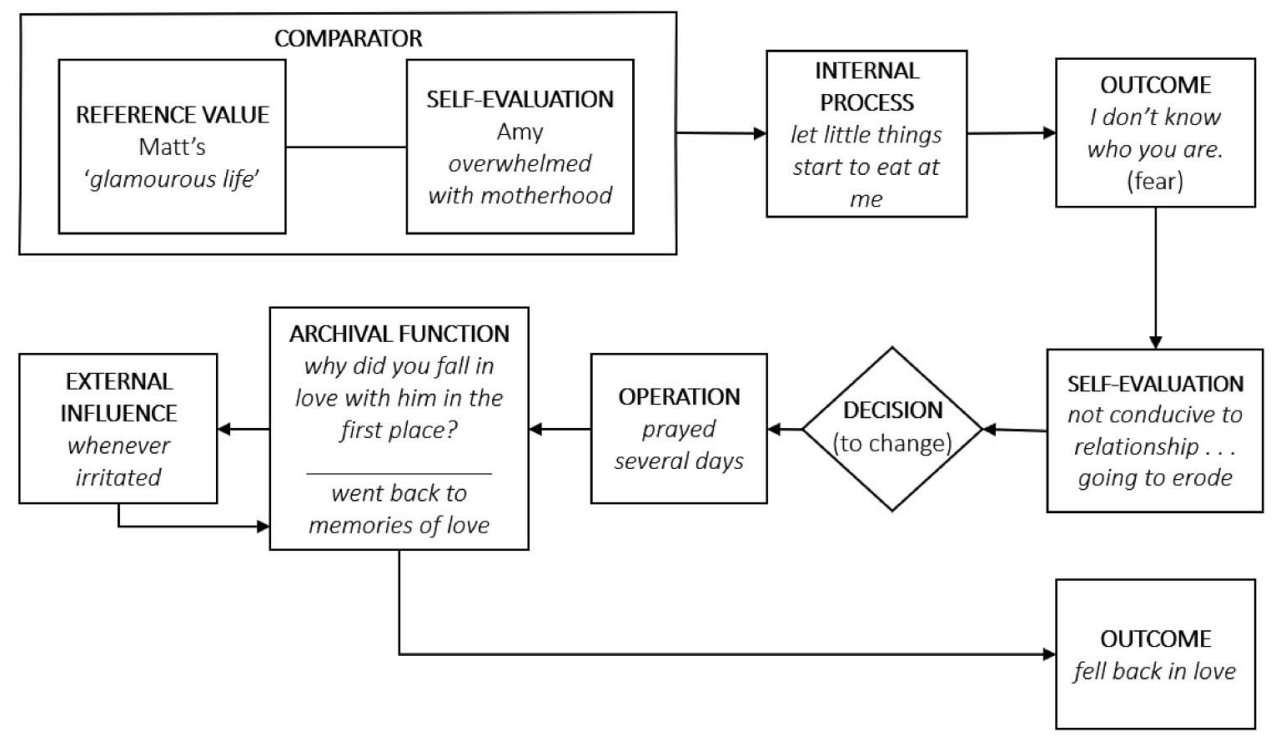

Figure 3. Relationship self-regulation process_- "falling out of love and back in love again" (Episode 3).

ther, our findings reflected how religion influenced hierarchical organization and subdivision of goals (McCullough \& Willoughby, 2009). Particularly, an abstract, higher order goal such as eternal marriage was pursued through achieving subgoals such as returning to religious observance, sincerely praying and reflecting, and then adopting and maintaining new patterns of religious and relational life.

Our findings indicate that important cognitive and emotional regulatory processes during selfmonitoring preceded behavioral changes (Wilson et al., 2005). For Amy, prayer as a religious practice cognitively facilitated self-examination and self-regulation to then change her feelings toward Matt and their marriage. In terms of emotional regulation, Amy's frightening realization that her thoughts and emotions regarding Matt and their marriage were not where she wanted them to be reportedly motivated her to pray for "many days." Further, Amy "on receiving answers to prayer" decided to retrieve memories of love from archival functions and used them to change her behavior, suggesting that storage and retrieval of these beliefs were equally important aspects of self-regulation.

For Matt, the importance of his religious belief in (and hope for) eternal marriage facilitated the sanctification of marriage, that is viewing marriage as sacred (Mahoney, 2013). These religious beliefs and hopes also reportedly fostered an ideal of marital permanence, which have been known to influence relationship effort, an aspect of self-regulation (Willoughby, 2015). Further, for both Amy and Matt, relational efforts were preceded with important decisions, which reiterate the agentic selforganizing nature of individuals and couples in the family system (Broderick, 1993). It seems likely that these agency-based efforts and decisions helped resist inadvertent relationship entropy and unintended dissolution.

Working together to preserve their marriage by reconnecting with their predefined goals, Amy and Matt were involved in a dyadic process, which we term relationship coregulation. Their goal of building an eternal marriage was both religious and relational, which they worked to achieve together. Furthermore, coordinated attempts at improving themselves and their relationship as a whole implied individual self-regulatory processes coupled with coregulatory processes. This is an important finding from this study, as it acknowledges the relational nature of coregulation because previous studies on coregulation have usually been limited to physiological and emotional aspects (Schoebi, 2008; Sbarra \& Hazan, 2008). More- 
over, the construct of relationship self-regulation could be interpreted as an individualistic approach to regulation if not for its relational directionality. In this regard, we propose relationship coregulation for a relational focus at all levels and processes of regulation.

\section{Clinical Implications}

For religious couples, this article suggests that drawing on relevant religious beliefs, practices, and even supportive faith community involvement can assist in both relationship selfregulation and relationship coregulation. Counselors can assist religious couples to draw from client's religious resources, meanings, and communities to strengthen self-regulation in ways that may benefit couple relationships. Of course, there are both harmful and helpful implications of religion for relationships (Dollahite et al., 2018), and we urge therapists to be aware of both to avoid harmful integrations of religion while utilizing potential benefits, via beliefs, practices, or communities (Dollahite, Marks, \& Goodman, 2004).

Religious and spiritual assessments may help to understand whether religion or spirituality are important aspects of clients' lives (Hodge, 2017). Then, based on the clients' values and preferences, approaches to therapy can be adapted to work with religious clients (Nielsen, Johnson, \& Ellis, 2001; Walsh, 2010). When working with religious clients, Richards and Bergin (2014) recommended the following competencies: (a) understand the diversity of religious traditions with respect; (b) examine how the client's worldview influences their identity, lifestyle, and emotional and interpersonal functioning; (c) avoid assumptions based solely on religious affiliation; and (d) explore religious and spiritual concerns that hinder, as well as resources that help, clients. Nonreligious couples may create meaning in their relationship, as suggested by Walsh (2010), through secular humanist values that can be explored in therapy through open-ended questions such as, "How do you find meaning, purpose, and connection in your life?", "When overstressed or depleted, how do you find tranquility, balance, and nourishment?", and "When going through hard times, how do you find strength and courage?" (Walsh, 2010, p. 344).
Another implication of this study is the importance of the processes involved in relationship coregulation. Therapists may help clients to work on shared relational coregulation processes by setting couple goals, evaluating and monitoring, choosing alternatives, and engaging in joint decision-making. Further, encouraging clients to develop personal and couple regulatory skills may be of value in helping couples to (a) have a shared vision for how better to work together, (b) have a clear set of operations to work on together, and (c) have a shared language for their future efforts to improve their couple processes. Attachment-based approaches such as emotionally focused therapy and mindfulness interventions may aid in processing difficult emotions and thereby help couples improve relationship self-regulation and coregulation (Greenman, Johnson, \& Wiebe, 2019).

\section{Limitations}

This study has several limitations. As a case study of a couple from one faith community, findings from this study severely limit generalizability to other religious traditions and family contexts. Further, there may be other relational aspects such as sacrifice and commitment, regardless of religion, that may have important influences in explaining relationship selfregulation. Our study may not capture these factors, as text-map analysis is limited to examining sequences and processes, which is different from inductive approaches to qualitative data. This intense focus on specific processes can unintentionally overlook larger overarching phenomena.

Findings from this study are not causal or conclusive. Text-maps depict sequential ordering of events as reported by participants using careful analysis of participant statements. This may allow for a kind of causal inference we call "stated sequential causality" (participant states that Factor A led to Factor B). However, because these data are not longitudinal, they cannot allow for establishing temporal causality (something at Time 1 causes something at Time 2 ). As a result, text-map analysis does not replace the need for longitudinal quantitative methods to test relationships between constructs. Finally, text-map analysis is a new tool 
that requires further scrutiny and development to become a robust methodology.

\section{Future Directions}

In the current trend of research on relationship self-regulation, most studies have focused largely or even solely on behavioral aspects, whereas cognitive and emotional aspects of self-regulation have typically been marginalized or neglected. Future quantitative work can consider cognitive, affective, and behavioral aspects as well as examine potential factors and effects of relationship self-regulation and coregulation. In addition to a more expansive view of relationship self-regulation, researchers may also consider the influence of belief systems such as religion that may influence relational goals and regulatory processes. Future theorizing and research may also explore connections between relational hope and agency and relational entropy as aspects of relationship selfregulation and coregulation.

\section{Conclusion}

Text-map analysis may be helpful to document systemic processes such as relationship self-regulation. We observed that in the pursuit of shared relational goals, dyadic relationships consist of important coregulatory processes. Research on relationship self-regulation and coregulation offers bright prospects for implications in therapy and practice. We are hopeful that systemic perspectives of couple regulation can guide and inform theory and help couples enjoy healthy relationship functioning and flourishing. We have also introduced text-map analysis as a research tool and hope that it may find a place in the repertoire of therapists and researchers.

\section{References}

Abbott, A. (1995). Sequence analysis: New methods for old ideas. Annual Review of Sociology, 21, 93-113. http://dx.doi.org/10.1146/annurev.so.21 .080195 .000521

Boisvert, C., \& Ahmed, M. (2019). Using diagrams in psychotherapy. New York, NY: Routledge.

Broderick, C. B. (1993). Understanding family process: Basics of family systems theory. Thousand Oaks, CA: Sage.
Carver, C. S., \& Scheier, M. F. (2001). On the self-regulation of behavior. New York, NY: Cambridge University Press.

Daly, K. J. (2007). Qualitative methods for family studies and human development. Atlanta, GA: Sage.

Dollahite, D. C., Marks, L. D., \& Barrow, B. H. (2019). Exploring Relational Reconciliation Processes in Christian, Jewish, and Muslim Families. Family Relations, 68, 517-533.

Dollahite, D. C., Marks, L. D., \& Dalton, H. (2018). Why religion helps and harms families: A conceptual model of a system of dualities at the nexus of faith and family life. Journal of Family Theory and Review, 10, 219-241. http://dx.doi.org/10.1111/jftr .12242

Dollahite, D. C., Marks, L. D., \& Goodman, M. (2004). Religiosity and families: Relational and spiritual linkages in a diverse and dynamic cultural context. In M. J. Coleman \& L. H. Ganong (Eds.), The handbook of contemporary families (pp. 411431). Thousand Oaks, CA: Sage.

Geyer, A. L., \& Baumeister, R. F. (2005). Religion, morality, and self-control: Values, virtues, and vices. In R. F. Paloutzian \& C. L. Park (Eds.), Handbook of the psychology of religion and spirituality (pp. 412-432). New York, NY: Guilford Press.

Girgždè, V., Keturakis, V., \& Sondaité, J. (2014). Couples' relationship self-regulation narratives after intervention. Europe's Journal of Psychology, 10, 336-351. http://dx.doi.org/10.5964/ejop.v10i2 .643

Greenman, P. S., Johnson, S. M., \& Wiebe, S. (2019). Emotionally focused therapy for couples: At the heart of science and practice. In B. H. Fiese, M. Celano, K. Deater-Deckard, E. N. Jouriles, \& M. A. Whisman (Eds.), APA handbooks in psychology series. APA handbook of contemporary family psychology: Family therapy and training (pp. 291-305). Washington, DC: American Psychological Association. http://dx.doi.org/10.1037/ 0000101-018

Halford, W. K., Lizzio, A., Wilson, K. L., \& Occhipinti, S. (2007). Does working at your marriage help? Couple relationship self-regulation and satisfaction in the first 4 years of marriage. Journal of Family Psychology, 21, 185-194. http://dx.doi .org/10.1037/0893-3200.21.2.185

Hardy, N. R., Soloski, K. L., Ratcliffe, G. C., Anderson, J. R., \& Willoughby, B. J. (2015). Associations between family of origin climate, relationship self-regulation, and marital outcomes. Journal of Marital and Family Therapy, 41, 508-521. http://dx.doi.org/10.1111/jmft.12090

Hodge, D. (2017). Spiritual competence: The key to effective practice with people from diverse religious backgrounds. In B. R. Crisp (Ed.), The Routledge handbook of religion, spirituality and social 
work (pp. 282-290). New York, NY: Taylor and Francis.

Impett, E. A., Gordon, A. M., Kogan, A., Oveis, C., Gable, S. L., \& Keltner, D. (2010). Moving toward more perfect unions: Daily and long-term consequences of approach and avoidance goals in romantic relationships. Journal of Personality and Social Psychology, 99, 948-963. http://dx.doi.org/ 10.1037/a0020271

Impett, E. A., Kogan, A., English, T., John, O., Oveis, C., Gordon, A. M., \& Keltner, D. (2012). Suppression sours sacrifice: Emotional and relational costs of suppressing emotions in romantic relationships. Personality and Social Psychology Bulletin, 38, 707-720. http://dx.doi.org/10.1177/ 0146167212437249

Korzybski, A. (1994). Science and sanity: An introduction to non-aristotelian systems and general semantics (5th ed.). Brooklyn, New York: Institute of General Semantics.

Kramer, B. J. (1993). Expanding the conceptualization of caregiver coping: The importance of relationship-focused coping strategies. Family Relations, 42, 383-391. http://dx.doi.org/10.2307/ 585338

Laurin, K., Kay, A. C., \& Fitzsimons, G. M. (2012). Divergent effects of activating thoughts of God on self-regulation. Journal of Personality and Social Psychology, 102, 4-21. http://dx.doi.org/10.1037/ a0025971

Leonhardt, N. D., Kirchner, E. R., Phillips, T. M., Skipper, A. D., Dollahite, D. C., \& Marks, L. D. (2018). Together forever: Eternal perspective and sacred practices in American Latter-day Saint families. Marriage and Family Review, 54, 719-732. http://dx.doi.org/10.1080/01494929.2018.1469575

Levitt, H. M., Bamberg, M., Creswell, J. W., Frost, D. M., Josselson, R., \& Suárez-Orozco, C. (2018). Journal article reporting standards for qualitative primary, qualitative meta-analytic, and mixed methods research in psychology: The APA publications and communications board task force report. American Psychologist, 73, 26-46. http://dx .doi.org/10.1037/amp0000151

Lofland, J., Snow, D. A., Anderson, L., \& Lofland, L. H. (2005). Analyzing social settings: A guide to qualitative observation and analysis (4th ed.). Belmont, CA: Wadsworth Publishing.

Mahoney, A. (2013). The spirituality of us: Relational spirituality in the context of family relationships. In K. I. Pargament, J. J. Exline, \& J. W. Jones (Eds.), APA handbook of psychology, religion, and spirituality: Vol. 1. Context, theory, and research (pp. 365-389). Washington, DC: American Psychological Association. http://dx.doi.org/ 10.1037/14045-020

McCullough, M. E., \& Willoughby, B. L. B. (2009). Religion, self-regulation, and self-control: Associ- ations, explanations, and implications. Psychological Bulletin, 135, 69-93. http://dx.doi.org/10 $.1037 / \mathrm{a} 0014213$

Nielsen, S. L., Johnson, W. B., \& Ellis, A. (2001). Counseling and psychotherapy with religious persons: A rational emotive behavior therapy approach. New York, NY: Routledge. http://dx.doi .org/10.4324/9781410600707

Novak, J. R., Smith, H. M., Larson, J. H., \& Crane, D. R. (2018). Commitment, forgiveness, and relationship self-regulation: An actor partner interdependence model of relationship virtues and relationship effort in couple relationships. Journal of Marital and Family Therapy, 44, 353-365. http:// dx.doi.org/10.1111/jmft.12258

Oster, G. D., \& Crone, P. G. (2004). Using drawings in assessment and therapy: A guide for mental health professionals. New York, NY: Routledge. http://dx.doi.org/10.4324/9780203341049

Pitney, W. A. (2004). Strategies for establishing trustworthiness in qualitative research. Athletic Therapy Today, 9, 26-28. http://dx.doi.org/10 .1123/att.9.1.26

Richards, P. S., \& Bergin, A. E. (2014). Religious diversity and psychotherapy: Conclusions, recommendations, and future directions. In P. S. Richards \& A. E. Bergin (Eds.), Handbook of psychotherapy and religious diversity (2nd ed., pp. 475-487). Washington, DC: American Psychological Association. http://dx.doi.org/10.1037/14371019

Sbarra, D. A., \& Hazan, C. (2008). Coregulation, dysregulation, self-regulation: An integrative analysis and empirical agenda for understanding adult attachment, separation, loss, and recovery. Personality and Social Psychology Review, 12, 141-167. http://dx.doi.org/10.1177/1088868308315702

Schoebi, D. (2008). The coregulation of daily affect in marital relationships. Journal of Family Psychology, 22, 595-604. http://dx.doi.org/10.1037/ 0893-3200.22.3.595

Shafer, K., James, S. L., \& Larson, J. H. (2016). Relationship self-regulation and relationship quality: The moderating influence of gender. Journal of Child and Family Studies, 25, 11451154. http://dx.doi.org/10.1007/s 10826-0150294-4

Tavory, I., \& Timmermans, S. (2014). Abductive analysis: Theorizing qualitative research. Chicago, IL: University of Chicago Press. http://dx .doi.org/10.7208/chicago/9780226180458.001 .0001

Townsend, E., Wadman, R., Sayal, K., Armstrong, M., Harroe, C., Majumder, P., . . . Clarke, D. (2016). Uncovering key patterns in self-harm in adolescents: Sequence analysis using the Card Sort Task for Self-harm (CaTS). Journal of Affective 
Disorders, 206, 161-168. http://dx.doi.org/10 .1016/j.jad.2016.07.004

Walsh, F. (2010). Spiritual diversity: Multifaith perspectives in family therapy. Family Process, 49, 330-348. http://dx.doi.org/10.1111/j.1545-5300 .2010.01326.x

Willoughby, B. J. (2015). The role of marital beliefs as a component of positive relationship function- ing. Journal of Adult Development, 22, 76-89. http://dx.doi.org/10.1007/s10804-014-9202-1

Wilson, K. L., Charker, J., Lizzio, A., Halford, K., \& Kimlin, S. (2005). Assessing how much couples work at their relationship: The behavioral selfregulation for effective relationships scale. Journal of Family Psychology, 19, 385-393. http://dx.doi .org/10.1037/0893-3200.19.3.385

\section{Appendix}

\section{Semi-Structured Interview Protocol for Couples}

(1) What are some of your beliefs relating to marriage/family?

(2) Are there practices or traditions that hold special meaning for you as a couple/family?

(3) Has your relationship with other important people in your lives influenced your relationship with each other? If so, how?

(4) What are the greatest challenges (external/internal) to your marriage and family being all you want it to be?

(5) All couples have some conflict. Are there ways that your beliefs or practices help avoid or reduce marital conflict?

(6) In trying to be a good marital partner and a good parent, from whom or where do you seek guidance?

(7) What values or beliefs are most important to the success of your marriage/ parenting?

(8) As parents, do you strive to share your deepest beliefs with your children? If so, how?
(9) Have your deepest beliefs helped you when your kids have struggled for meaning or guidance?

(10) Has your relationship with others influenced your relationship with your children? (Vice versa, example?)

(11) How important to you is it that your child(ren) follow in your beliefs?

(12) What are your deepest hopes for your child(ren) in relation to their future family life?

(13) To the mother: What do you consider to be the most important things for you to be or do as a mother?

(14) To the father: What do you consider to be the most important things for you to be or do as a father?

(15) What do your most meaningful conversations with your child center on?

Received May 9, 2019

Revision received December 27, 2019

Accepted January 19, 2020 